\title{
Rencana Teknis dan Ekonomi Reklamasi pada Tambang Emas PT X di Kecamatan Simpenan, Kabupaten Sukabumi, Provinsi Jawa Barat
}

\author{
Dendi Syahriadi* \\ Prodi Teknik Pertambangan, Fakultas Teknik, Universitas Islam \\ Bandung, Indonesia. \\ *dendy_1997@live.com
}

\begin{abstract}
PT X is a private mining company engaged in gold metal mineral mining located in Simpenan District. Sukabumi Regency. West Java Province, the area that is planned for mining is 8.7 hectares consisting of 10 mining blocks for a period (10 years). where at the end of the mining activity stage reclamation will be carried out. The purpose of this research is to plan a technical plan for land management. revegetation. care and maintenance in a former mining activity area where reclamation activities will be carried out, so that from the technical activity plan it can find out the total cost required for the reclamation activity plan from an economic point of view, the technical plan for reclamation is carried out from 2022-2031. the reclamation area is in accordance with the area being mined for a period (10 years). The total area to be reclaimed is $8.7 \mathrm{Ha}$. Based on the results of the research, it can be concluded that at the land use stage, equipment in the form of the Kobelco SK330 Excavator, Hino 500 - FM260JD Dump Truck, and Komatsu D85PX-18 Bulldozer will be used. In the revegetation stage, the plants used include tea plants (Camelia Sinensis), insert plants such as Eucalyptus trees (Musa acuminata) and cover crops in the form of legumes (Melaleuca Leucadendra). This technical plan for reclamation will continue to plant care and maintenance so that plant growth can be optimal and the success of reclamation is $100 \%$. The total cost for this reclamation plan is Rp. $1,348,737,035,-$. .,
\end{abstract}

Keywords: Reclamation, Land Manangement, Revegetation.

\begin{abstract}
Abstrak. PT X merupakan perusahaan tambang swasta yang bergerak pada bidang pertambangan mineral logam emas yang berlokasi di kecamatan simpenan, Kabupaten sukabumi, Provinsi Jawa Barat. Luasan area yang direncanakan dilakukan penambangan yaitu seluas 8,7 Ha yang terdiri atas 10 blok penambangan selama satu periode (10 Tahun), dimana pada akhir tahapan kegiatan penambangan akan dilakukan reklamasi. Tujuan dari penelitian ini yaitu merencanakan suatu rencana teknis reklamasi berupa penataan lahan, revegetasi serta perawatan, dan pemeliharaan pada suatu area bekas kegiatan penambangan. sehingga dari rencana kegiatan teknis tersebut dapat mengetahui total biaya yang dibutuhkan untuk rencana kegiatan reklamasi ditinjau dari sisi ekonomi. Rencana teknis reklamasi dilakukan dari tahun 2022-2031, luas area reklamasi sesuai dengan luas area yang dilakukan penambangan selama satu periode (10 tahun). Luas total yang akan direklamasi 8,7 Ha. Berdasarkan hasil penelitian dapat disimpulkan bahwa pada tahapan penataan lahan akan digunakan peralatan mekanis berupa Excavator Kobelco SK330, Dump Truck Hino 500 - FM260JD, dan Bulldozer Komatsu D85PX-18. Pada tahapan revegetasi tanaman yang digunakan antara lain, yaitu tanaman pokok berupa tanaman teh (Camelia Sinensis), tanaman sisipan berupa pohon Kayu Putih (Musa acuminata) dan tanaman penutup berupa tanaman Kacang-kacangan (Melaleuca Leucadendra). Rencana teknis reklamasi ini akan dilanjutkan hingga tahapan perawatan dan pemeliharaan tanaman revegetasi agar pertumbuhan tanaman dapat optimal dan tercapainya keberhasilan reklamasi sebesar $100 \%$. Adapun anggaran total biaya rencana reklamasi ini dibutuhkan sebesar Rp 1.348.737.035,--
\end{abstract}

Kata Kunci: Reklamasi, Penataan Lahan, Revegetasi. 


\section{A. Pendahuluan}

PT X adalah salah satu perusahaan tambang logam emas yang terletak di Kecamatan Simpenan, Kabupaten Sukabumi, Provinsi Jawa Barat. Kegiatan penambangan perusahaan menggunakan sistem penambangan tambang terbuka (surface mining) dengan quarry. Kegiatan penambangan dapat menyebabkan perubahan bentang alam secara fisik morfologi dan topografi lahan yang dapat mengganggu ekosistem alam, sehingga diperlukan kegiatan reklamasi dimulai dari penataan lahan hingga penanaman kembali.

Pada lokasi penelitian akan dilakukannya kegiatan pertambangan selama satu periode (10 tahun) oleh sebab itu diperlukannya rencana teknis dan ekonomi reklamasi. Kajian reklamasi tambang untuk mengembalikan alih fungsi lingkungan mengacu pada PP No.78 Tahun 2010 dan Kepmen No. 1827/K/30/MEM/2018 mengenai standar reklamasi dan pascatambang.

Berdasarkan latar belakang yang telah diuraikan, maka perumusan masalah dalam penelitian ini adalah : "Bagaimana rencana teknis dan ekonomi reklamasi lahan bekas tambang emas terhadap kesesuaiannya dengan UU No.03 Tahun 2020 dan Kepmen No. 1827/K/30/MEM/2018?".

Adapun tujuan dalam penelitian ini sebagai berikut.

1. Mengetahui rencana teknis kegiatan penatagunaan lahan.

2. Mengetahui rencana teknis kegiatan revegetasi.

3. Mengetahui rencana teknis pemeliharaan revegetasi.

4. Mengetahui rencana total biaya yang dibutuhkan untuk kegiatan reklamasi.

\section{B. Metodologi Penelitian}

Metodologi penelitian yang digunakan oleh penulis dalam penelitian skripsi adalah sebagai berikut:

1. Teknik Pengambilan Data

Teknik pengambilan data terbagi menjadi 2 kelompok, yaitu data primer dan data sekunder. Berdasarkan sumber untuk memperoleh datanya, data primer dan data sekunder dibedakan sebagai berikut:

a. Data Primer

Pengambilan data primer yaitu dengan melakukan observasi dan melakukan wawancara dengan pengawas guna pengambilan, data topografi dan morfologi daerah, peta rencana penambangan, dokumen rencana reklamasi (RRRT), dokumen studi kelayakan (feasibility study), harga peralatan dan perlengkapan kebutuhan revegetasi.

b. Data Sekunder

Pengambilan data sekunder yaitu dengan cara mengkaji data/laporan terdahulu. Data sekunder meliputi Undang-Undang Minerba (UU-Minerba), peraturan pemerintah (PP), Peraturan Menteri ESDM (Permen ESDM), Peraturan daerah (Perda), Spesifikasi alat mekanis, flora dan fauna endemik daerah penelitian.

2. Teknik Pengolahan Data

Dilakukan dengan cara merencanakan teknis kegiatan reklamasi pada area yang telah ditentukan berdasarkan peta rencana penambangan. Serta merencanakan anggaran biaya yang dibutuhkan, meliputi biaya penatagunaan lahan, biaya revegetasi dan biaya pemeliharaan dan perawatan sehingga mendapatkan total biaya rencana kegiatan reklamasi.

3. Teknik Analisis Data

Dilakukan dengan cara menggunakan teknik komparatif atau perbandingan antara luasan area penambangan yang dibuka ( $8,7 \mathrm{Ha})$ dengan luasan yang direklamasi, dengan hasil akhir berupa rencana teknis dan ekonomi kegiatan reklamasi. Diagram alir penelitian dapat dilihat pada Gambar 1.1 Diagram Alir Penelitian.

\section{Hasil Penelitian dan Pembahasan}

\section{Luasan Area Penambangan dan Reklamasi}


Berdasarkan hasil penelitian yang dilakukan, rencana luasan area bukaan tambang dan juga luasan reklamasi dapat dilihat pada tabel 1.

Tabel 1. Rencana Luas Penambangan dan Reklamasi

\begin{tabular}{|c|c|c|c|}
\hline Tahun & Lokasi & $\begin{array}{c}\text { Rencana Luas } \\
\text { Bukaan Tambang } \\
\text { (Ha) }\end{array}$ & $\begin{array}{c}\text { Recana Luas } \\
\text { Reklamasi } \\
\text { (Ha) }\end{array}$ \\
\hline 2022 & 1 & 0,87 & - \\
\hline 2023 & 2 & 0,87 & 0,87 \\
\hline 2024 & 3 & 0,87 & 0,87 \\
\hline 2025 & 4 & 0,87 & 0,87 \\
\hline 2026 & 5 & 0,87 & 0,87 \\
\hline 2027 & 6 & 0,87 & 0,87 \\
\hline 2028 & 7 & 0,87 & 0,87 \\
\hline 2029 & 8 & 0,87 & 0,87 \\
\hline 2030 & 9 & 0,87 & 0,87 \\
\hline 2031 & 10 & 0,87 & 1,74 \\
\hline & Total (Ha) & $\mathbf{8 , 7}$ & $\mathbf{8 , 7}$ \\
\hline
\end{tabular}

\section{Kebutuhan Material Reklamasi}

Kebutuhan material reklamasi terdiri atas overburden dan topsoil. Lapisan overburden digunakan pada kegiatan penataan lahan, sedangkan top soil digunakan pada tahapan penebaran sebagai sumber hara bagi tanaman revegetasi. Kebutuhan material reklamasi yang telah dihitung dapat dilihat pada tabel 2 .

Tabel 2. Kebutuhan Material Reklamasi

\begin{tabular}{|c|c|c|c|c|}
\multirow{2}{*}{ Tahun } & \multicolumn{2}{|c|}{$\begin{array}{c}\text { Kebutuhan Material } \\
\text { Reklamasi (LCM) } \\
\text { Overburden }\end{array}$} & \multicolumn{2}{c|}{$\begin{array}{c}\text { Kebutuhan Material } \\
\text { Pemadatan }\end{array}$} \\
& 9.560 & Overburden & Top Soil \\
\hline 2022 & 9.560 & 4.780 & - & - \\
\hline 2023 & 9.560 & 4.780 & 8.700 & 4.350 \\
\hline 2024 & 9.560 & 4.780 & 8.700 & 4.350 \\
\hline 2025 & 9.560 & 4.780 & 8.700 & 4.350 \\
\hline 2026 & 9.560 & 4.780 & 8.700 & 4.350 \\
\hline 2027 & 9.560 & 4.780 & 8.700 & 4.350 \\
\hline 2028 & 9.560 & 4.780 & 8.700 & 4.350 \\
\hline 2029 & 9.560 & 4.780 & 8.700 & 4.350 \\
\hline 2030 & 9.560 & 4.780 & 8.700 & 4.350 \\
\hline 2031 & 19.120 & 9.560 & 17.400 & 8.700 \\
\hline Total & $\mathbf{3 8 . 2 4 2}$ & $\mathbf{1 9 . 1 2 1}$ & $\mathbf{3 4 . 8 0 0}$ & $\mathbf{1 7 . 4 0 0}$ \\
\hline
\end{tabular}

\section{Produktivitas Peralatan Mekanis}

Peralatan mekanis yang dilakukan dalam kegiatan reklamasi ini, yaitu Excavator Kobelco SK330 dengan produktivitas 148,97 LCM/Jam/Alat, kemudian Dumptruck Hino 500 FM260JD dengan produktivitas 36,10 LCM/Jam/Alat, serta Bulldozer Komatsu D85PX-18 dengan nilai produktivitas sebesar139,61 LCM/Jam/Alat. Hasil perhitungan produktivitas peralatan mekanis dapat dilihat pada tabel 3, tabel 4 dan tabel 5 .

Tabel 3. Produktivitas Excavator Kobelco SK330

\begin{tabular}{|c|l|c|c|}
\hline \multicolumn{2}{|c|}{ Parameter } & Nilai & Satuan \\
\hline \multirow{2}{*}{$\begin{array}{c}\text { Excavator } \\
\text { Kobelco } \\
\text { SK330 }\end{array}$} & Kapasitas Bucket $\left(\mathrm{H}_{\mathrm{m}}\right)$ & 1,6 & LCM \\
\cline { 2 - 4 } & Fill Factor $\left(\mathrm{FF}_{\mathrm{m}}\right)$ & 90 & $\%$ \\
\cline { 2 - 4 } & Swell Factor $(\mathrm{SF})$ & 80 & $\%$ \\
\hline
\end{tabular}




\begin{tabular}{|l|c|c|} 
Efisiensi Kerja $\left(\mathrm{E}_{\mathrm{m}}\right)$ & 81,25 & $\%$ \\
\hline \multirow{2}{*}{ Cycle Time $(\mathrm{CT})$} & 22,62 & detik \\
\cline { 2 - 3 } & 0,38 & menit \\
\hline Produktivitas $(\mathbf{P m} 1)$ & $\mathbf{1 4 8 , 9 7}$ & LCM/Jam/Alat \\
\hline
\end{tabular}

Tabel 4. Produktivitas Dumptruck Hino 500 FM260JD

\begin{tabular}{|c|l|c|c|}
\hline \multicolumn{2}{|l}{ Parameter } & Nilai & Satuan \\
\hline \multirow{4}{*}{ Hino 500 } & Kapasitas Vessel $\left(\mathrm{H}_{\mathrm{a}}\right)$ & 10 & LCM \\
\cline { 2 - 4 } & Kapasitas Bucket $\left(\mathrm{H}_{\mathrm{m}}\right)$ & 1,6 & LCM \\
\cline { 2 - 4 } & Fill Factor $\left(\mathrm{FF}_{\mathrm{m}}\right)$ & 90 & $\%$ \\
\cline { 2 - 4 } & Swell Factor $(\mathrm{SF})$ & 80 & $\%$ \\
\cline { 2 - 4 } & Efisiensi Kerja $\left(\mathrm{E}_{\mathrm{a}}\right)$ & 81,25 & $\%$ \\
\cline { 2 - 4 } & Jumlah Pemuatan $\left(\mathbf{n}_{\mathrm{p}}\right)$ & $\mathbf{6}$ & - \\
\cline { 2 - 4 } & Kembali Kosong $\left(\mathrm{T}_{\mathrm{k}}\right)$ & 1,95 & menit \\
\cline { 2 - 4 } & Manuver Kosong $\left(\mathrm{T}_{\mathrm{mk}}\right)$ & 0,75 & menit \\
\cline { 2 - 4 } & Pemuatan $\left(\mathrm{T}_{\mathrm{l}}\right)$ & 2,15 & menit \\
\cline { 2 - 4 } & Berangkat Isi $\left(\mathrm{T}_{\mathrm{i}}\right)$ & 2,65 & menit \\
\cline { 2 - 4 } & Manuver Isi $\left(\mathrm{T}_{\mathrm{mi}}\right)$ & 0,60 & menit \\
\cline { 2 - 4 } & Pengosongan $\left(\mathrm{T}_{\mathrm{d}}\right)$ & 0,65 & menit \\
\cline { 2 - 4 } & Cycle Time $(\mathbf{C T})$ & $\mathbf{8 , 7 5}$ & menit \\
& Produktivitas $\left(\mathbf{P}_{\mathrm{a}} \mathbf{1}\right)$ & $\mathbf{3 6 , 1 0}$ & LCM/Jam/Alat \\
\hline
\end{tabular}

Tabel 5. Produktivitas Bulldozer D85PX-18

\begin{tabular}{|c|c|c|c|}
\hline \multicolumn{2}{|r|}{ Parameter } & Nilai & Satuan \\
\hline \multirow{10}{*}{$\begin{array}{c}\text { Bulldozer } \\
\text { Komatsu } \\
\text { D85PX- } \\
18\end{array}$} & Blade Capacity $(\mathrm{H})$ & 5,2 & LCM \\
\hline & Forward Speed $(\mathrm{F})$ & 50 & $\mathrm{~m} / \mathrm{menit}$ \\
\hline & Reverse Speed (R) & 83,33 & $\mathrm{~m} / \mathrm{menit}$ \\
\hline & Waktu Ganti Gigi (Z) & 0,1 & menit \\
\hline & Grade Factor (e) & 95 & $\%$ \\
\hline & Efisiensi Kerja $\left(E_{a}\right)$ & 81,25 & $\%$ \\
\hline & Swell Factor (SF) & 80 & $\%$ \\
\hline & $\begin{array}{l}\text { Jarak Pergerakan } \\
\text { Bulldozer (D) }\end{array}$ & 40 & $\mathrm{~m}$ \\
\hline & Cycle Time (CT) & 1,38 & menit \\
\hline & Produktivitas (Pa1) & 139,61 & LCM/Jam/Alat \\
\hline
\end{tabular}

\section{Penataan Lahan}

Upaya untuk meratakan kembali area bekas kegiatan penggalian maupun penambangan maka dilakukan kegiatan penataan lahan. Alat yang digunakan pada penataan lahan yaitu bulldozer dengan kebutuhan bahan bakarnya sebesar 28 liter/jam, kemudian rencana pengerjaan penataan lahan akan dilakukan selama 89 hari. Rencana dari penataan lahan dapat dilihat pada tabel 6.

Tabel 6. Penataan Lahan

\begin{tabular}{|c|c|c|c|c|c|}
\hline \multirow{2}{*}{ Parameter } & Tahun I & Tahun II & Tahun III & Tahun IV & Tahun V \\
\cline { 2 - 6 } & $\mathbf{2 0 2 2}$ & $\mathbf{2 0 2 3}$ & $\mathbf{2 0 2 4}$ & $\mathbf{2 0 2 5}$ & $\mathbf{2 0 2 6}$ \\
\hline Luas (Ha) & - & 0,87 & 0,87 & 0,87 & 0,87 \\
\hline Volume (LCM) & - & $9.560,44$ & $9.560,44$ & $9.560,44$ & $9.560,44$ \\
\hline Waktu Operasi Alat (Jam) & - & 68,48 & 68,48 & 68,48 & 68,48 \\
\hline Kebutuhan Bahan Bakar (L) & - & $1.917,47$ & $1.917,47$ & $1.917,47$ & $1.917,47$ \\
\hline
\end{tabular}

JRTP is licensed under Creative Commons Attribution-

NonCommercial-ShareAlike 4.0 International License. 


\begin{tabular}{|c|c|c|c|c|c|}
\hline Total Waktu Pengerjaan (Hari/Tahun) & - & 9 & 9 & 9 & 9 \\
\hline Parameter & Tahun VI & Tahun VII & Tahun VIII & Tahun IX & Tahun X \\
\hline Luas (Ha) & $\mathbf{2 0 2 7}$ & $\mathbf{2 0 2 8}$ & $\mathbf{2 0 2 9}$ & $\mathbf{2 0 3 0}$ & $\mathbf{2 0 3 1}$ \\
\hline Volume (LCM) & 0,87 & 0,87 & 0,87 & 0,87 & 1,74 \\
\hline Waktu Operasi Alat (Jam) & $9.560,44$ & $9.560,44$ & $9.560,44$ & $9.560,44$ & $19.120,88$ \\
\hline Kebutuhan Bahan Bakar (L) & $1.917,47$ & $1.917,47$ & $1.917,47$ & $1.917,47$ & $3.834,95$ \\
\hline Total Waktu Pengerjaan (Hari/Tahun) & 9 & 9 & 9 & 9 & 17 \\
\hline $\begin{array}{c}\text { Total Pengerjaan Selama 10 Tahun } \\
\text { (Hari) }\end{array}$ & & & 89 & & \\
\hline
\end{tabular}

\section{Penebaran Top Soil}

Setelah dilakukan penataan lahan, kemudian dilakukan kegiatan penebaran top soil. Penebaran top soil yaitu untuk menebarkan tanah pada area yang sudah dilakukan penataan lahan, dimana tanah yang digunakan tanah humus sebagai sumber hara untuk tanaman revegetasi. Alat yang digunakan pada penataan lahan yaitu excavator, dumptruck, dan bulldozer di mana pemakaian bahan bakar untuk excavator sebesar 25 liter/jam, dumptruck 12 liter/jam, dan bulldozer sebesar 28 liter/jam, di mana rencana pengerjaan penebaran top soil akan dilakukan selama 120 hari. Rencana dari penebaran topsoil dapat dilihat pada tabel 7.

Tabel 7. Penebaran Topsoil

\begin{tabular}{|c|c|c|c|c|c|c|}
\hline \multirow{2}{*}{$\begin{array}{c}\text { Alat } \\
\text { Mekanis }\end{array}$} & \multirow{2}{*}{ Parameter } & Tahun I & Tahun II & $\begin{array}{l}\text { Tahun } \\
\text { III }\end{array}$ & $\begin{array}{c}\text { Tahun } \\
\text { IV }\end{array}$ & Tahun V \\
\hline & & 2022 & 2023 & 2024 & 2025 & 2026 \\
\hline \multirow{13}{*}{$\begin{array}{c}\text { Excavator } \\
\text { Kobelco } \\
\text { SK330 }\end{array}$} & Luas (Ha) & - & 0,87 & 0,87 & 0,87 & 0,87 \\
\hline & Volume (LCM) & - & $4.780,22$ & $4.780,22$ & $4.780,22$ & $4.780,22$ \\
\hline & Waktu Operasi Alat (Jam) & - & 32,09 & 32,09 & 32,09 & 32,09 \\
\hline & Kebutuhan Bahan Bakar (L) & - & 802,24 & 802,24 & 802,24 & 802,24 \\
\hline & $\begin{array}{c}\text { Total Waktu Pengerjaan } \\
\text { (Hari/Tahun) }\end{array}$ & - & 4 & 4 & 4 & 4 \\
\hline & \multirow[t]{2}{*}{ Parameter } & $\begin{array}{l}\text { Tahun } \\
\text { VI }\end{array}$ & Tahun VII & Tahun VIII & Tahun IX & Tahun X \\
\hline & & 2027 & 2028 & 2029 & 2030 & 2031 \\
\hline & Luas (Ha) & 0,87 & 0,87 & 0,87 & 0,87 & 1,74 \\
\hline & Volume (LCM) & $4.780,22$ & $4.780,22$ & $4.780,22$ & $4.780,22$ & $9.560,44$ \\
\hline & Waktu Operasi Alat (Jam) & 32,09 & 32,09 & 32,09 & 32,09 & 64,18 \\
\hline & Kebutuhan Bahan Bakar (L) & 802,24 & 802,24 & 802,24 & 802,24 & $1.604,47$ \\
\hline & $\begin{array}{c}\text { Total Waktu Pengerjaan } \\
\text { (Hari/Tahun) }\end{array}$ & 4 & 4 & 4 & 4 & 8 \\
\hline & Total Pengerjaan (Hari) & & & 40 & & \\
\hline \multirow{2}{*}{ Alat Mekanis } & \multirow{2}{*}{ Parameter } & Tahun I & Tahun II & Tahun III & Tahun IV & Tahun V \\
\hline & & 2022 & 2023 & 2024 & 2025 & 2026 \\
\hline \multirow{13}{*}{$\begin{array}{c}\text { Dumptruck } \\
\text { Hino 500 } \\
\text { FM260JD }\end{array}$} & Luas (Ha) & - & 0,87 & 0,87 & 0,87 & 0,87 \\
\hline & Volume (LCM) & - & $4.780,22$ & $4.780,22$ & $4.780,22$ & $4.780,22$ \\
\hline & Waktu Operasi Alat (Jam) & - & 33,10 & 33,10 & 33,10 & 33,10 \\
\hline & Kebutuhan Bahan Bakar (L) & - & $1.588,87$ & $1.588,87$ & $1.588,87$ & $1.588,87$ \\
\hline & $\begin{array}{c}\text { Total Waktu Pengerjaan } \\
\text { (Hari/Tahun) }\end{array}$ & - & 4 & 4 & 4 & 4 \\
\hline & \multirow[t]{2}{*}{ Parameter } & $\begin{array}{l}\text { Tahun } \\
\text { VI }\end{array}$ & Tahun VII & Tahun VIII & Tahun IX & Tahun X \\
\hline & & 2027 & 2028 & 2029 & 2030 & 2031 \\
\hline & Luas (Ha) & 0,87 & 0,87 & 0,87 & 0,87 & 1,74 \\
\hline & Volume (LCM) & $4.780,22$ & $4.780,22$ & $4.780,22$ & $4.780,22$ & $9.560,44$ \\
\hline & Waktu Operasi Alat (Jam) & 33,10 & 33,10 & 33,10 & 33,10 & 66,20 \\
\hline & Kebutuhan Bahan Bakar (L) & $1.588,87$ & $1.588,87$ & $1.588,87$ & $1.588,87$ & $3.177,73$ \\
\hline & $\begin{array}{c}\text { Total Waktu Pengerjaan } \\
\text { (Hari/Tahun) }\end{array}$ & 4 & 4 & 4 & 4 & 8 \\
\hline & Total Pengerjaan (Hari) & & & 40 & & \\
\hline
\end{tabular}




\begin{tabular}{|c|c|c|c|c|c|c|}
\hline \multirow{2}{*}{ Alat Mekanis } & \multirow{2}{*}{ Parameter } & Tahun I & Tahun II & Tahun III & Tahun IV & Tahun V \\
\hline & & 2022 & 2023 & 2024 & 2025 & 2026 \\
\hline \multirow{13}{*}{$\begin{array}{c}\text { Bulldozer } \\
\text { Komatsu } \\
\text { D85PX-18 }\end{array}$} & Luas (Ha) & - & 0,87 & 0,87 & 0,87 & 0,87 \\
\hline & Volume (LCM) & - & $4.780,22$ & $4.780,22$ & $4.780,22$ & $4.780,22$ \\
\hline & Waktu Operasi Alat (Jam) & - & 33,10 & 33,10 & 33,10 & 33,10 \\
\hline & Kebutuhan Bahan Bakar (L) & - & 958,74 & 958,74 & 958,74 & 958,74 \\
\hline & $\begin{array}{c}\text { Total Waktu Pengerjaan } \\
\text { (Hari/Tahun) }\end{array}$ & - & 4 & 4 & 4 & 4 \\
\hline & \multirow{2}{*}{ Parameter } & $\begin{array}{l}\text { Tahun } \\
\text { VI }\end{array}$ & Tahun VII & Tahun VIII & Tahun IX & Tahun X \\
\hline & & 2027 & 2028 & 2029 & 2030 & 2031 \\
\hline & Luas (Ha) & 0,87 & 0,87 & 0,87 & 0,87 & 1,74 \\
\hline & Volume (LCM) & $4.780,22$ & $4.780,22$ & $4.780,22$ & $4.780,22$ & $9.560,44$ \\
\hline & Waktu Operasi Alat (Jam) & 33,10 & 33,10 & 33,10 & 33,10 & 66,20 \\
\hline & Kebutuhan Bahan Bakar (L) & 958,74 & 958,74 & 958,74 & 958,74 & $1.917,47$ \\
\hline & $\begin{array}{c}\text { Total Waktu Pengerjaan } \\
\text { (Hari/Tahun) }\end{array}$ & 4 & 4 & 4 & 4 & 9 \\
\hline & Total Pengerjaan (Hari) & \multicolumn{5}{|c|}{41} \\
\hline \multicolumn{2}{|c|}{ Total Pengerjaan (Hari) } & \multicolumn{5}{|c|}{121} \\
\hline
\end{tabular}

\section{Revegetasi}

Kegiatan penanaman kembali pada suatu lahan yang sudah dilakukan penataan lahan dan penebaran top soil disebut sebagai revegetasi. Kegiatan revegetasi terdiri atas pengadaan bibit tanaman pokok berupa tanaman teh (camelia sinensis), tanaman sisipan berupa kayu putih (malaleuca leucadendra), dan tanapan penutup berupa kacang-kacangan (mucuna bracteata), dilanjutkan dengan kegiatan penanaman dan pemberian pupuk hingga perawatan dan pemeliharaan. Untuk melihat waktu yang dibutuhkan dalam melakukan revegetasi dapat dilihat pada tabel 8 .

Tabel 8. Revegetasi

\begin{tabular}{|c|c|c|c|c|c|c|c|c|c|c|c|}
\hline \multirow{3}{*}{ Kegiatan } & \multirow{3}{*}{ Alat } & \multicolumn{10}{|c|}{ Waktu Pengerjaan (Hari) } \\
\hline & & Tahun & Tahun & Tahun & Tahun & Tahun & Tahun & Tahun & Tahun & Tahun & Tahun \\
\hline & & 2022 & 2023 & 2024 & 2025 & 2026 & 2027 & 2028 & 2029 & 2030 & 2031 \\
\hline Penataan Lahan & $\begin{array}{c}\text { Tanaman } \\
\text { Pokok }\end{array}$ & - & 87 & 87 & 87 & 87 & 87 & 87 & 87 & 87 & 174 \\
\hline \multirow{3}{*}{$\begin{array}{l}\text { Penebaran } \\
\text { Tanah Pucuk }\end{array}$} & $\begin{array}{l}\text { Tanaman } \\
\text { Sisipan }\end{array}$ & - & 5 & 5 & 5 & 5 & 5 & 5 & 5 & 5 & 10 \\
\hline & $\begin{array}{l}\text { Tanaman } \\
\text { Penutup }\end{array}$ & - & 0 & 0 & 0 & 0 & 0 & 0 & 0 & 0 & 0 \\
\hline & $\begin{array}{c}\text { Pemeliharaan } \\
\text { dan } \\
\text { Perawatan }\end{array}$ & - & 6 & 6 & 6 & 6 & 6 & 6 & 6 & 6 & 6 \\
\hline \multicolumn{2}{|c|}{ Total Hari Pertahun } & - & 98 & 98 & 98 & 98 & 98 & 98 & 98 & 98 & 190 \\
\hline \multicolumn{2}{|c|}{ Total Hari Selama 10 Tahun } & \multicolumn{10}{|c|}{974} \\
\hline
\end{tabular}

\section{Total Biaya Reklamasi}

Total biaya reklamasi merupakan jumlah keseluruhan biaya yang dibutuhkan pada tahapan penataan lahan, penebaran top soil, dan revegetasi. Total biaya yang dibutuhkan adalah sebesar Rp 1.348.737.035,-. Total biaya reklamasi dapat dilihat pada tabel 9.

Tabel 9. Revegetasi 


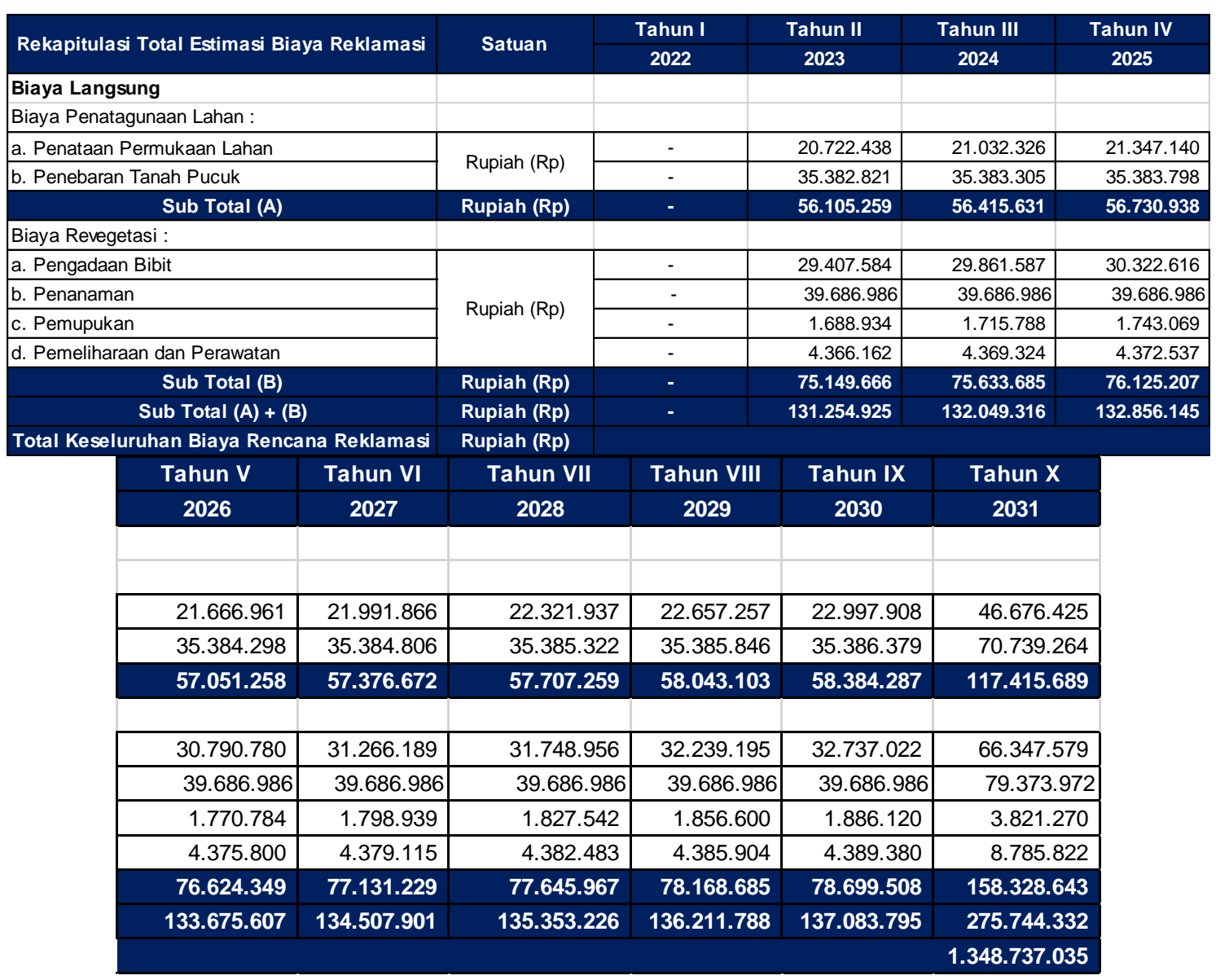

\section{Kesimpulan}

Kesimpulan yang didapatkan dari hasil penelitian, yaitu :

1. Rencana teknis penatagunaan lahan reklamasi dilakukan pada tahun 2022-2031 dengan luas total 8,7 Ha.

2. Rencana teknis revegetasi dilakukan pada tahun 2023-2031 tanaman yang digunakan pada kegiatan revegetasi, yaitu tanaman teh (camelia sinensis), tanaman kayu putih (melaleuca leucadendra), dan Tanaman Kacang-kacangan (mucuna bracteata).

3. Rencana teknis pemeliharaan dan perawatan dilakukan pada tahun 2023-2031, meliputi pemupukan, penyulaman, penyiraman, serta pemberian insektisida tanaman.

4. Total biaya reklamasi pada tahun 2023-2031 sebesar Rp 1.348.737.035,-.

\section{Daftar Pustaka}

[1] Anonim, 2020, “Undang-Undang Nomor 3 Tahun 2020 Tentang Perubahan Undang-Undang Nomor 4 Tahun 2009 (Pertambangan Mineral dan Batubara)" Pemerintah Republik Indonesia, Jakarta, Indonesia.

[2] Anonim, 2010, "Peraturan Pemerintah Nomor 78 Tahun 2010 tentang Reklamasi dan Pascatambang", Pemerintah Republik Indonesia, Jakarta, Indonesia.

[3] Anonim, 2018, "Keputusan Menteri Energi dan Sumber Daya Mineral Republik Indonesia Nomor 1827 K/30/MEM/2018 Tentang Pedoman Pelaksanaan Kaidah Teknik Pertambangan yang Baik". Kementerian Energi dan Sumber Daya Mineral Republik Indonesia, Jakarta, Indonesia.

[4] Anonim, 2012, "Peraturan Daerah Kabupaten Bogor Nomor 22 Tahun 2012 Tentang Rencana Tata Ruang Wilayah (RTRW) Kabupaten Sukabumi Tahun 2012-2032”. Pemerintahan Daerah Kabupaten Sukabumi, Indonesia.

[5] Anonim, 2020, "Kobelco SK330 Specification", Kobelco Construction Machinery, Tokyo, Japan. 
[6] Anonim, 2020, "Hino 500 FM260JD Spefication", Hino Motor Industries, Tokyo, Japan.

[7] Anonim, 2020, "Komatsu D85PX-18 Specification", Komatsu Industries, Tokyo, Japan.

[8] Priyono, dkk, 2002, "Panduan Kehutanan Indonesia", Badan Penelitian dan Pengembangan Kehutanan dan Perkebunan, Kementerian Kehutanan dan Lingkungan Hidup, Jakarta, Indonesia.

[9] Prodjosumarto, Partanto. 1993, "Pemindahan Tanah Mekanis", Jurusan Teknik Pertambangan Fakultas Teknologi Mineral, Institut Teknologi Bandung, Bandung. 